\title{
Solar Radiation Prediction Models Analysis for Varying Climatic Conditions
}

\author{
Patrick M. Wainaina ${ }^{\# 1}$, George. O. Owino ${ }^{* 2}$, Musa.R.Njue ${ }^{\# 3}$ \\ ${ }^{\# 1}$ Department of Industrial and Energy Engineering, Faculty of Engineering and Technology \\ (Egerton University, Kenya.) \\ ${ }^{* 2}$ Department of Industrial and Energy Engineering, Faculty of Engineering and Technology \\ (Egerton University, Kenya.) \\ ${ }^{\# 3}$ Department of Agricultural Engineering, Faculty of Engineering and Technology \\ (Egerton University, Kenya). \\ Corresponding author E-mail address; wainainapatrick13@gmail.com
}

\begin{abstract}
:
This study has investigated global solar predictive models, modified, validated and compared five models, for prediction of monthly daily mean solar radiation in four different locations of Kenya that represents the four major climatic conditions. The input variables to the models were; latitude, day length, sunshine hours, relative sunshine hours, temperature, and precipitation. Solar radiation data from 2000 to 2013 was used to obtain the monthly daily mean global solar radiation, to analyze, validate and compare the performance of the models. The predicted and measured data was simulated using MATLAB. Statistical indicators, MBE, RMSE, t-test and $\mathrm{R}$, were performed to determine the models performance. The results showed that sunshine hours based models predicted global solar radiation with higher accuracy in wet and cold, wet and warm climatic conditions, while the temperature and precipitation models were accurate in solar radiation prediction in hot and dry climatic conditions.
\end{abstract}

Key words: Global solar radiation1, Sunshine hours2, Day length3

\section{INTRODUCTION}

Solar radiation energy is the direct abundant and permanent form of energy resource available on the earth due to the nuclear fusion on the sun. The sun receives about one hundred thousand TW of this renewable energy. The clouds, gases, and pollution in the atmosphere decrease this energy to less than 800 times the energy available on earth surface [1].

Solar radiation data for different locations is required for many applications such as calculation of water budget, architectural engineering, determination for power levels in PV modules, and calculation of cooling load in buildings [2]. The design of solar energy application systems requires precise data and knowledge of the available global solar radiation at the location of interest for accurate design of the systems [3].

Solar radiation is only measured by a few weather stations in developing countries due to economic and historical reasons, particularly in remote areas of the developing countries [4]. The study of solar radiation under local meteorological conditions is essential as the solar radiation reaching the earth surface depends on the local meteorological conditions [5]. For this reason, location where meteorological data is unavailable, solar radiation can be estimated from models and empirical correlations based on available data. Several formulated models have been explored for estimation of solar radiation with reasonable accuracy from available meteorological data. However, most of the models require astronomical and physical parameters that are unavailable in most developing countries [6], [7].

According to [8], [9], meteorological parameters used as inputs in the relationships includes; astronomic (solar constant, world sun distance, solar declination and hour angle); geographical (latitude, longitude and altitude); geometric (surface azimuth, surface tilt angle, solar altitude and solar azimuth); physical (albedo, scatterings of 
air and water vapour molecules, dust and pollution); meteorological (Air temperature, precipitation, cloudiness, sunshine duration and humidity). Solar radiation using irradiative transfer models and satellites has also been used by [10], [11]. Meteorological variable data that is most available in most meteorological stations include air temperature, sunshine duration and the geometrical parameters of a location. [12]- [14] proposed an empirical model based on physical and geographical variables of a location. Artificial neural network with climatic variables of temperature and relative atmospheric pressure model for estimation of solar radiation was formulated by [15], but atmospheric pressure variation is difficult to predict in remote meteorological centers [6].

Most models find limited applications in developing countries due to unavailability of data in astronomical parameters such as sky transmittance, albedo, relative atmospheric pressure, clearness index and cloudiness index [15]. Parameters frequently investigated include cloud cover, sunshine duration, day-length, temperature, precipitation and geographical parameters [3]. According to [16], most solar radiation estimation models are cloud cover and sunshine duration based. However, cloud cover observation data is not available in most meteorological stations [6], [7]. The complexity in computation and lack of sufficient data, have discouraged the use of most of the empirical correlation and some models in existence [17].

This paper has investigated, modified and validated five different global solar radiation models, for prediction of monthly daily mean solar radiation in four different locations of Kenya, based sunshine duration, day-length and latitude of a location, ambient air temperature and precipitation as the input variables in the models. These are some of the geometrical and meteorological data available in most meteorological stations. Preliminary investigation of the models under literature review indicated low performance in prediction of global solar radiation compared to the measured global solar radiation. There was therefore need to modify the empirical constants for these models. The models were trained with four years data obtained from national aeronautics and space authority NASA, Surface Solar radiation and Energy SSE and optimized with MATLAB and validated with five years monthly daily mean solar radiation. The relative performance of the five models was analyzed by RMSE, MBE, t- test and R statistical indicators.

\section{Methodology}

The methodology is discussed in two sections under two major sub heading. The first subheading deals with the five models description while the second subheading describes the acquisition of data and treatment.

\section{A. Models Description}

Five models utilizing geographical and climatic variables with different variable combinations were investigated. The basic characteristic of the models is the correlation of global solar radiation with the geographical; (latitude, longitude, Altitude), physical; (sunshine duration, day-length, air temperature, and precipitation) as the input variables. Each of the four locations that represent the major climatic conditions of Kenya was investigated for each of the five models.

The original Angstrom-Prescott regression equation relating monthly average solar radiation of a clear day radiation is formulated as an average fraction of possible sunshine hours, based on extraterrestrial radiation on a horizontal surface is expressed by[17]) in equation 1.

$$
\frac{H}{H_{o}}=a+b \frac{S}{S_{o}}
$$

Where $H$ and $H_{o}$ are the monthly daily mean global solar radiation and the extraterrestrial solar radiations in $W / m^{2}$ respectively. $S$ and $S_{o}$ are monthly daily mean sunshine duration and day-length in hour. $a$ is a constant that represents the overall atmospheric transmission while $b$ represents the rate of increase of $\frac{H}{H_{0}}$ with $\frac{S}{S_{o}}$.

$H_{o}$ was expressed by [17] as in equation 2 . 


$$
H_{o}=\frac{24}{\pi} I_{s c}\left[1+0.033 \cos \frac{306 n}{365}\right]\left[\cos \varphi \cos \delta \sin \omega_{s}+\frac{\pi}{180} \omega_{s} \sin \varphi \sin \delta\right]
$$

$I_{s c}$ is the solar constant $=1365 \mathrm{~W} / \mathrm{m}^{2}, \varphi$ is the latitude of the location in degrees, $\delta$ is the solar declination angle, $\omega$ the monthly mean sunset hour and $n$ is the number of days of the year from first January.

According to[18], $\delta, \omega_{s}$ and $S_{o}$ are expressed by;

$$
\begin{aligned}
& \delta=23.45 \sin \left[360\left(\frac{284+n}{365}\right)\right] \\
& \omega_{s}=\cos ^{-1}(-\tan \varphi \tan \delta) \\
& S_{o}=\frac{2}{15} \omega_{s}
\end{aligned}
$$

The empirical constants $a$ and $b$ were determined from the location geographical, physical variables.

Sunshine duration is the period during which the direct solar radiation exceeds the threshold of $120 \mathrm{~W} / \mathrm{m}^{2}$ per day [19]. Different models describing monthly mean solar radiation are paraphrased as shown in the five models;

\section{Rietveld model;}

The first model considered was formulated by [12] and it described global solar radiation in terms of sunshine duration and day-length

$$
\begin{aligned}
& a=0.10+0.48 \frac{S}{S_{o}}(6) \\
& b=0.38+0.08 \frac{S}{S_{o}}
\end{aligned}
$$

The global solar radiation was thus expressed as;

$$
H=H_{o}\left(0.1+0.48 \frac{S}{S_{o}}+0.38+0.08 \frac{S}{S o}\right)
$$

\section{Gariepy Model;}

The second model describing global solar radiation with air temperature $\left(T^{O} C\right)$ and precipitation $(P \mathrm{~mm})$ was formulated by [20].

$$
\begin{aligned}
& H=H_{o}(0.3791-0.0041 T-0.017 P+0.4810-0.0043 T+0.0097 P) . \\
& a=0.3791-0.0041 T-0.017 P \\
& b=0.4810-0.0043 T+0.0097 P
\end{aligned}
$$

Hence the global solar radiation was expressed as; 


\section{Rensheng Model;}

The third model suggested by [21], described global solar radiation in terms of the following variables; latitude

$(\varphi)$, longitude $(L)$, altitude $(h)$ in $\mathrm{km}$.

$$
H=H_{o}\left[\left(0.0007 \varphi+2.44 \times 10^{-2} L-0.005 h+2.24 \times 10^{-5} L+0.370\right)+1.026\left(\frac{S}{S_{0}}\right)^{2}+0.778\left(\frac{S}{S_{o}}\right)^{3}\right]
$$

\section{Elagib and Mansell Model;}

Elagib and Mansell model established monthly specific model for each month of the year was published by [22].

$$
H=H_{0}\left[0.1357+0.3204 \varphi+0.422 L+0.4947\left(\frac{S}{S_{o}}\right)\right]
$$

\section{Almorox Model;}

The fifth model that was investigated, considered specific model for each month of the year as established by [3] in terms of relative sunshine hours as in equation 13.

$$
H=H_{o}\left[0.285+0.444\left(\frac{S}{S_{o}}\right)\right]
$$

\section{B. Data Accusation and Validation}

Monthly daily mean global solar radiation, ambient air temperatures and precipitation for four locations in Kenya was obtained from NASA, SSE and from some meteorological stations from January $1^{\text {st }} 2000$ to December $30^{\text {th }} 2013$.

\section{Methodology}

The monthly daily means; sunshine hours, day length, temperature, precipitation, longitude and altitude for each of the four sites in Kenya were obtained from each meteorological centers data base from $1^{\text {st January }} 2000$ to $31^{\text {st }}$ December 2006. The corresponding monthly daily mean global solar radiation of the four sites from

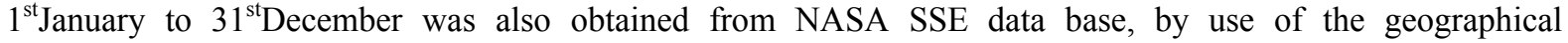
coordinates. The prediction of monthly daily mean global solar radiation for each of the five models; Rietveld, Rensheng, Elagib, Almorox and Gariepy was obtained by inputting sunshine, day length, latitude, longitude temperature and precipitation in MATLAB programs. The coefficients of each of the five models were modified by training and optimization each of the model in each of the four climatic conditions in Kenya. $1^{\text {st }}$ January 2007 to $31^{\text {st }}$ December 2010 data was used in the MATLAB.

\section{B. Validation}

Each of the five modified models were validated in each of the four climatic conditions using NASA SSE data

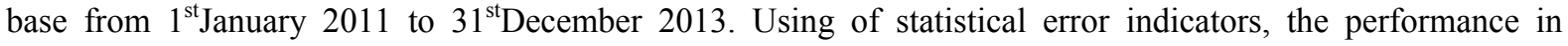
prediction of global solar radiation each of the model for the climatic conditions was evaluated.

\section{Model performance}

The performances of the models were evaluated on the basis of following statistical error indicators; Root mean square Error (RMSE), Mean biased error (MBE), t-test and R recommended by [23].

According to $[19,23]$, the Root mean square error (RMSE) measures the short term prediction quality of the correlation as is defined as; 


$$
R M S E=\left\{\left[\sum_{i=1}^{i=12}\left(I_{i m}-I_{i p}\right)^{2}\right] / N\right\}^{1 / 2}
$$

The Mean biased error (MBE) provides information of the long term performance models. A low MBE is ideal. A positive value gives the average of overestimation in the predicted values and vice versa [23]. MBE is defined as;

$$
M B E=\left[\sum_{i=1}^{i=12}\left(I_{i m}-I_{i p}\right)\right] / N
$$

The coefficient of correlation(R) can be used to determine the linear relationship between the measured and predicted global solar radiation and is evaluate from the following equation;

$$
R=\left[\frac{\sum\left(I_{m m}-I_{m p}\right)\left(I_{i m}-I_{m p}\right)}{\sqrt{\sum_{1}^{n}\left(I_{m p}-I_{i p}\right)^{2} \sqrt{\sum_{1}^{n}\left(I_{m m}-I_{i p}\right)^{2}}}}\right]
$$

$I_{m m} I_{i p} I_{m p}$ are mean measured solar radiation, predicted solar radiation and mean predicted solar radiation[24].

\section{Modified Models}

The modified monthly daily mean solar estimation models obtained from training and MATLAB optimization are as indicated in table I, and II.

Table I. Rietveld and Gariepy Modified Models

\begin{tabular}{|l|l|l|}
\hline \multicolumn{1}{|c|}{ Month } & \multicolumn{1}{|c|}{ Rietveld } & \multicolumn{1}{|c|}{ Gariepy } \\
\hline January & $0.571172\left[0.285+\left(S / S_{0}\right)\right]$ & $4.9747\left(a+b H_{0}\right)$ \\
\hline February & $0.556765\left[0.201+0.49\left(S / S_{0}\right)\right]$ & $4.4568\left(a+b H_{0}\right)$ \\
\hline March & $0.619496\left[0.201+0.491\left(S / S_{0}\right)\right]$ & $4.4568\left(a+b H_{0}\right)$ \\
\hline April & $0.600923\left[0.2+0.491\left(S / S_{0}\right)\right]$ & $4.2676\left(a+b H_{0}\right)$ \\
\hline May & $0.70947\left[0.256+0.475 S / S_{0}\right]$ & $4.2008\left(a+b H_{0}\right)$ \\
\hline June & $0.514747\left[0.33+439\left(S / S_{0}\right)\right]$ & $4.2543\left(a+b H_{0}\right)$ \\
\hline July & $0.578098\left[0.329+0.406\left(S / S_{0}\right)\right]$ & $4.5765\left(a+b H_{0}\right)$ \\
\hline August & $0.571735\left[0313+0.41\left(S / S_{0}\right)\right]$ & $4.4410\left(a+b H_{0}\right)$ \\
\hline September & $0.56443\left[0.217+0.479\left(S / S_{0}\right)\right]$ & $4.5862\left(a+b H_{0}\right)$ \\
\hline
\end{tabular}




\begin{tabular}{|l|l|l|}
\hline October & $0.781463\left[0.259+0,465\left(\frac{S}{S_{0}}\right)\right]$ & $4.4513\left(a+b H_{0}\right)$ \\
\hline November & $0.714637\left[0.279+0.411\left(S / S_{0}\right)\right]$ & $4.2669\left(a+b H_{0}\right)$ \\
\hline December & $0.61775\left[0.262+0.428 S / S_{0}\right]$ & $4.4635\left(a+b H_{0}\right)$ \\
$H_{0}=\left(\frac{24}{\lambda}\right) I_{s c}\left(1+1.033 \cos \left(\frac{360 \times D_{N}}{365}\right)\right) \cos (P) \cos (\delta) \sin \left(w_{s}\right)+\left(\frac{\lambda}{180}\right) w_{s} \sin (P) \sin (\delta)$
\end{tabular}

$P$ is latitude, $D_{N}$ is the day of the year $1^{\text {st }}$ January is $1, I_{s c}$ is solar constant $=1375 \mathrm{~W} / \mathrm{m}^{2}$

$$
\begin{aligned}
& \delta=23.45 \sin \left(\frac{360 \times 284\left(D_{N}-1\right)}{365}\right), w_{s}=\cos ^{-1}(-\tan P \tan \delta), \delta=23.5 \sin \left[\frac{360\left(284+D_{N}\right)}{365}\right] \\
& a=0.37022-0.00313 \delta, b=0.3209+0.00506 \delta \\
& \text { sn }=\sin (P) \sin (x) \cos (P)^{2} \cos (h s), h s=\cos ^{-1}[-1 \tan P \times \tan x]
\end{aligned}
$$

\begin{tabular}{|c|c|c|c|}
\hline \multicolumn{4}{|c|}{ Models } \\
\hline Month & Rengsheng & Elagib & Almorox \\
\hline Jan & $0.8288\left[a+b\left(S / S_{0}\right)\right] H$ & $3.93\left[I_{s c} S n 0.0457\left(t_{-}\right.\right.$solar $\left.)+0.0874\right]$ & $068\left[0.18+0.66\left(\mathrm{~S} / \mathrm{S}_{0}\right)\right]$ \\
\hline Feb & $0.79\left[a+b\left(\mathrm{~S} / \mathrm{S}_{0}\right)\right] H_{0}$ & $0.01\left[I_{s c} S n 0.0373\left(t_{-}\right.\right.$solar $\left.)+0.22245\right]$ & $0.67\left[0.22+0.58\left(\mathrm{~S} / \mathrm{S}_{0}\right)\right]$ \\
\hline Mar & $0.03\left[a+b\left(S / S_{0}\right)\right] H_{0}$ & $1.15\left[I_{s c} S n 0.0297\left(t_{-}\right.\right.$solar $\left.)+0.3074\right]$ & $0.66\left[0.22+0.58\left(\mathrm{~S} / \mathrm{S}_{0}\right)\right]$ \\
\hline Apl & $0.7854\left[a+b S / S_{0}\right] H_{0}$ & $0.1260\left[I_{s c} S n 0.016\left(t \_s o l a r\right)+0.474\right]$ & $0.65\left[0.2+0.62\left(\mathrm{~S} / \mathrm{S}_{0}\right)\right.$ \\
\hline May & $0.81\left[a+b\left(S / S_{0}\right)\right] H_{0}$ & $1.48\left[I_{\text {sc }}\right.$ Sn0.0258(t_solar $\left.)+0.3623\right]$ & $0.67\left[0.24+0.53\left(\frac{S}{S_{0}}\right)\right]$ \\
\hline Jun & $0.7243\left[a+b\left(S / S_{0}\right)\right] H$ & $1.3192\left[I_{s c} S n 0.02\left(t_{-}\right.\right.$Solar $\left.)+0.446\right]$ & $0.67\left[0.24+0.53\left(\mathrm{~S} / \mathrm{S}_{0}\right)\right]$ \\
\hline Jul & $0.8188\left[a+b\left(S / S_{o}\right)\right] H$ & $1.6523\left[I_{s c} S n 0.03(t\right.$ tsolar $\left.)+0.28\right]$ & $0.70137\left[0.23+0.55\left(\frac{S}{S_{0}}\right)\right.$ \\
\hline Aug & $0.79\left[a+b\left(S / S_{0}\right)\right] H_{0}$ & $2.0\left[I_{s c} S n 0.0307\left(t_{-} \text {solar }\right)_{-} 0.274\right]$ & $0.70\left[0.22+.55\left(\mathrm{~S} / \mathrm{S}_{0}\right)\right]$ \\
\hline
\end{tabular}

Table II. Rensheng, Elagib and Almorox Modified Models 


\begin{tabular}{|l|l|l|l|}
\hline Sep & $0.86\left[a+b\left(\mathrm{~S} / \mathrm{S}_{0}\right)\right] H_{0}$ & $2.23\left[I_{\text {sc }}\right.$ Sn0.031(t_solar $\left.)+0.2472\right]$ & $0.71\left[0.2+0.59\left(\mathrm{~S} / \mathrm{S}_{0}\right)\right]$ \\
\hline Oct & $0.82\left[a+b\left(\mathrm{~S} / \mathrm{S}_{b}\right)\right] H_{0}$ & $1.75\left[I_{\text {sc }}\right.$ sn0.02471(t_solar $\left.)+0.3354\right]$ & $0.70\left[0.19\left(\mathrm{~S} / \mathrm{S}_{o}\right)\right]$ \\
\hline Nov & $0.73\left[a+b\left(\mathrm{~S} / \mathrm{S}_{0}\right)\right] H_{0}$ & $1.81\left[I_{\text {sc }}\right.$ Sn0.0255(t_solar $\left.)+0.302\right]$ & $0.66\left[0.17+0.66\left(\mathrm{~S} / \mathrm{S}_{0}\right)\right]$ \\
\hline Dec & $\begin{array}{l}0.832 \\
0.83\left[a+b\left(\mathrm{~S} / \mathrm{S}_{0}\right)\right] H_{0}\end{array}$ & $5.48\left[I_{\text {sc }}\right.$ Sn00287(t_solar $\left.)+0.0676\right]$ & $0.67\left[0.18+0.65\left(\mathrm{~S} / \mathrm{S}_{0}\right)\right]$ \\
\hline
\end{tabular}

$a=0.3791-0.0041 T-0.0176 P, \quad b=0.498-0.043 T+0.0096 P$

The five modified models performance for each of the four climatic conditions namely, Kericho, Isiolo Mombasa and Nakuru are as shown in figures Figure 2(a), 2(b), 2(c) and 2(d).

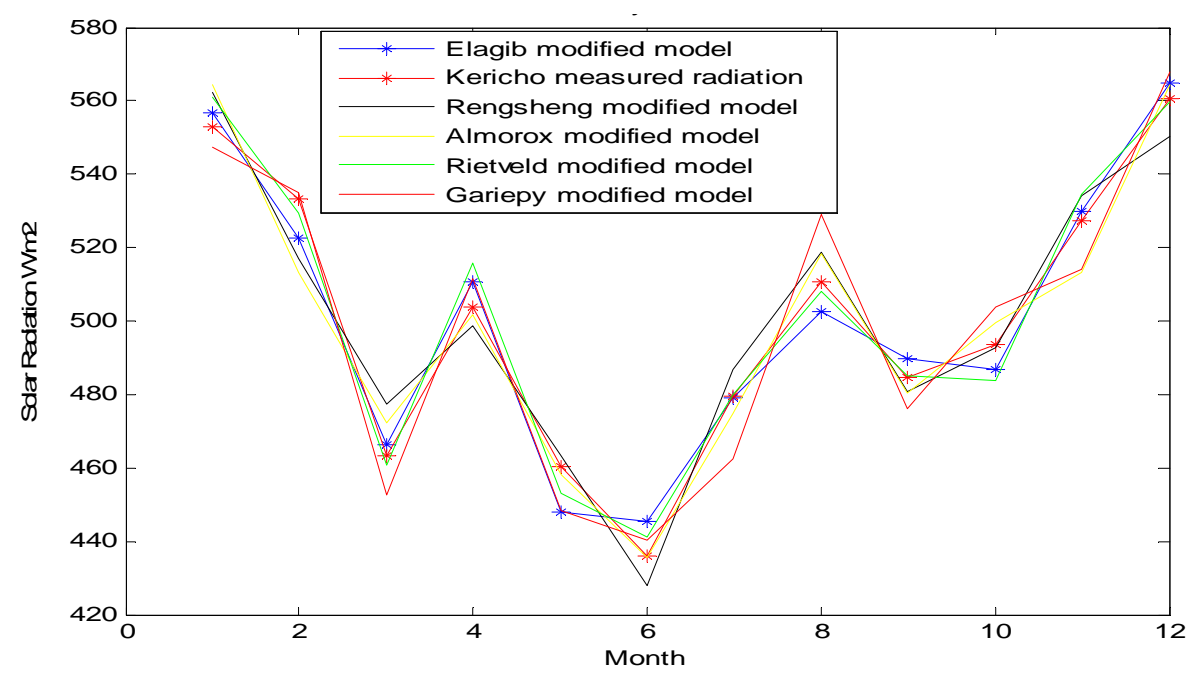

Fig2 (a) Kericho mean monthly direct solar radiation

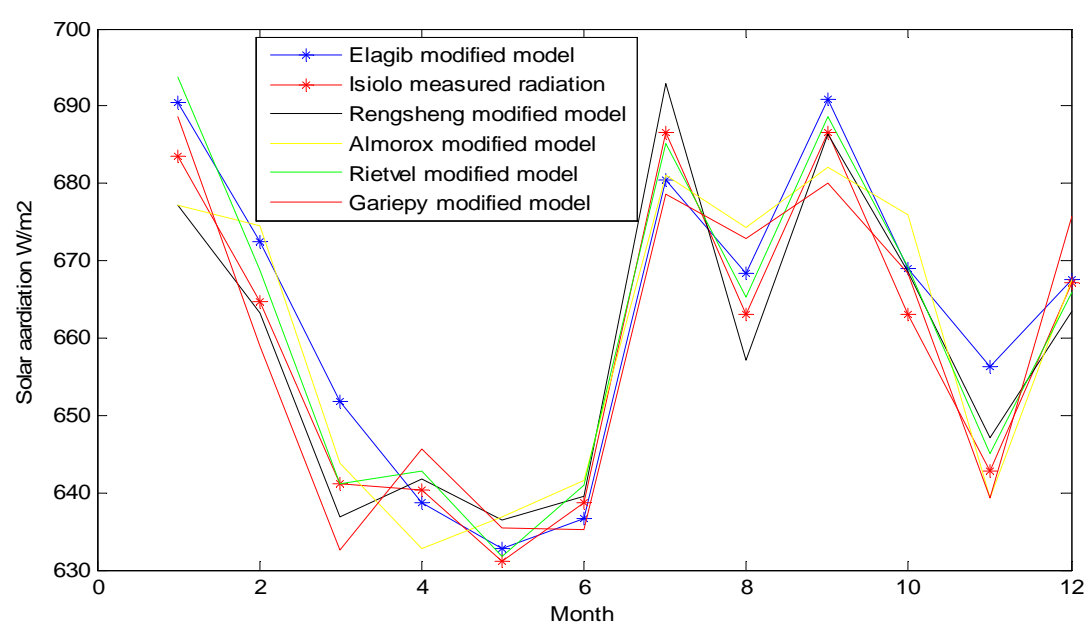

Fig2 (b) Isiolo mean monthly direct solar radiation 


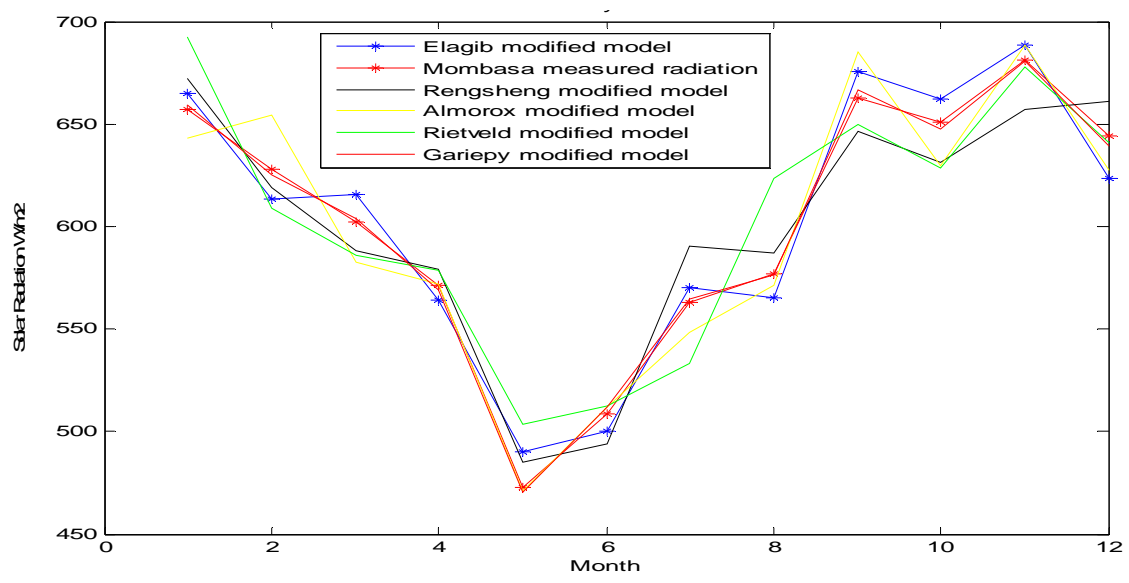

Fig2 (c) Mombasa mean monthly direct solar radiation

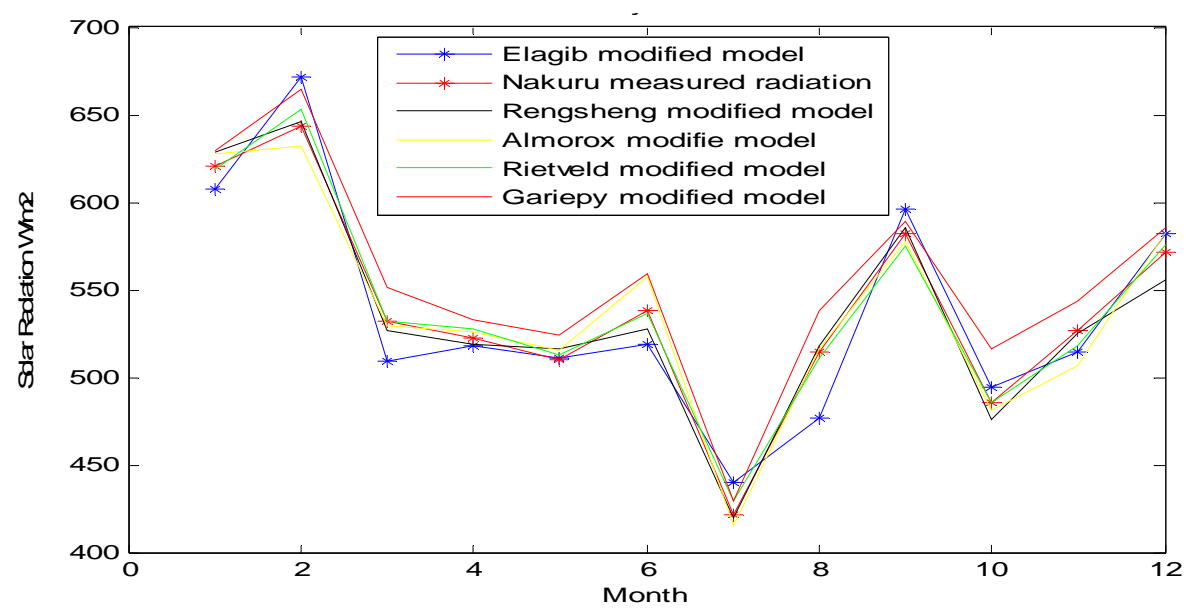

Fig 2(d) Nakuru mean monthly direct solar radiation

The performance of the five modified models in the four climatic conditions was evaluated by the following statistical error indicators; MBE, RMSE, $t$-statistics and the coefficient of correlation (R). Table III show the performance of the five modified models.

Table III. Models Performance from statistical indicators

\begin{tabular}{|c|c|c|c|c|c|}
\hline Climatic condition & Model & MBE & RMSE & t-test & $\mathrm{R}$ \\
\hline & Elagib & 5.5122 & 13.4732 & 2.2964 & 0.9919 \\
Isiolo & Rengsheng & 3.7980 & 0.6069 & 3.798 & 0.9962 \\
(Hot and dry) & Almorox & -1.5199 & 5.2650 & 0.7430 & 0.9914 \\
& Rietveld & -2.4748 & 8.5731 & 0.7431 & 0.9963 \\
& Gariepy & 1.1638 & 0.6025 & 3.776 & 0.9919 \\
\hline \multirow{3}{*}{ Kericho } & Elagib & 6.0922 & 0.9041 & 3.8946 & 0.8437 \\
(wet and cold) & Rengsheng & 7.7508 & 1.2810 & 3.3629 & 0.8377 \\
& Almorox & 0.8819 & 3.0550 & 1.3460 & 0.8345 \\
& Rietveld & -0.5351 & 1.8536 & 0.7430 & 0.8437 \\
& Gariepy & 9.6497 & 5.0222 & 6.9161 & 0.8436 \\
\hline
\end{tabular}




\begin{tabular}{|c|c|c|c|c|c|}
\hline & Elagib & 11.6521 & 4.0364 & 5.0748 & 0.8721 \\
Mombasa & Rengsheng & 9.5257 & 2.0090 & 3.3447 & 0.8726 \\
& Almorox & 2.7978 & 9.6920 & 1.3460 & 0.8710 \\
& Rietveld & -1.4272 & 4.9438 & 0.7430 & 0.8742 \\
& Gariepy & 2.5031 & 1.3727 & 7.344 & 0.8710 \\
& & & & & \\
\hline & & & & & 0.9756 \\
Nakuru & Elagib & 15.9304 & 8.0648 & 6.7171 & 0.9860 \\
& Rengsheng & 5.9994 & 7.0633 & 18.7036 & 0.9757 \\
& Almorox & 0.1353 & 0.4687 & 1.3460 & 0.9855 \\
& Rietveld & -0.6237 & 2.1604 & 0.7430 & 0.9874 \\
\hline
\end{tabular}

\section{Results and Discussions}

The determination of the model performance in prediction of monthly daily mean global solar radiation for the four climatic conditions was done by use of the most utilized statistical indicators of Root mean square error (RMSE), Mean biased error (MBS) $t$-test and coefficient of correlation (R) [25]. The short term error in prediction of global solar radiation was obtained from the RMSE, while the long term prediction error was determined by use of the MBE. In order to determine if the predicted global solar radiation had a significant difference to the measured global solar radiation; $t$-statistics was performed for the five models in each of the four climatic conditions is as shown in table 3. The coefficient of correlation R analyses was performed, to determine how close the predicted global solar radiation was to the measured global solar radiation showed a range of $0.9963 \mathrm{~W} / \mathrm{m}^{2}$ in Isiolo and a minimum of $0.8436 \mathrm{~W} / \mathrm{m}^{2}$ in Kericho as predicted by Gariepy modified model as shown in table3. This showed that the predicted global solar radiation value was close the measured global solar radiation.

The short term error in predicting the global solar radiation had a maximum of $13.472 \mathrm{~W} / \mathrm{m}^{2}$ by Elagib modified model in Isiolo, and a minimum of $0.4687 \mathrm{~W} / \mathrm{m}^{2}$ in Nakuru as predicted by Almorox modified model as from table 3. This error margins are small compared to the monthly daily mean global solar radiation of $500 \mathrm{~W} / \mathrm{m}^{2}$ in most climatic conditions. The long term error in prediction of the monthly daily mean global solar radiation was indicated by the MBE. As recorded in table 3, the highest error was in Nakuru predicted by Gariepy modified models whose value was $15.9307 \mathrm{~W} / \mathrm{m}^{2}$. A minimum of $0.1353 \mathrm{~W} / \mathrm{m}^{2}$ was registered in Nakuru by Almorox modified model. Comparing a monthly daily mean global solar radiation of $500 \mathrm{~W} / \mathrm{m}^{2}$ to an error range of $0.1353 \mathrm{~W} / \mathrm{m}^{2}$ to $15.9307 \mathrm{~W} / \mathrm{m}^{2}$ and the original Almorox model which was higher of 62.817 , than the modified models show better performance. The performance compares well with the estimates from [1] models.

The five modified models were classified into two categories; relative sunshine hours based models and the air temperature and pressure based models. The relative sunshine hours based models includes the following modified models; Elagib, Rengsheng, Almorox and Rietveld. Gariepy modified model was air temperature and pressure based model. From table III, the relative sunshine hours based models showed low RMSE and MBE values in both indicators for the wet climatic conditions regions. Almorox and Rietveld modified models showed a MBE range between 0.1353 to $0.8819 \mathrm{~W} / \mathrm{m}^{2}$, and a range of 1.853 to $3.0505 \mathrm{~W} / \mathrm{m}^{2}$ for RMSE in the wet climatic conditions. The Gariepy modified model which is air temperature and pressure based showed lowest values MBE of $1.1638 \mathrm{~W} / \mathrm{m}^{2}$ in Isiolo and $2.5031 \mathrm{~W} / \mathrm{m}^{2}$ in Mombasa. The lowest RMSE values of 0.6025 $\mathrm{W} / \mathrm{m}^{2}$ was predicted in Isiolo while the lowest value of $1.3727 \mathrm{~W} / \mathrm{m}^{2}$ was predicted in Mombasa by Gariepy modified model. Except the Elagib modified models which showed MBE of $15.9307 \mathrm{~W} / \mathrm{m}^{2}$ and RMSE of $13.4732 \mathrm{~W} / \mathrm{m}^{2}$ other models showed MBE and RMSE values below $10 \mathrm{~W} / \mathrm{m}^{2}$. This indicates that relative sunshine based modified models have higher performance in prediction of monthly daily mean global solar radiation in Wet and warm, wet and cold climatic region, while air temperature and pressure based model has a higher performance in prediction of monthly daily mean global solar radiation in hot climatic conditions. This is influenced by high temperature range variation experienced in hot climatic conditions as compared to wet climatic conditions. The statistical indicators in the predictions are within the expected range compared to [25].

\section{Conclusion}

In this research, the performance in prediction of monthly daily mean global solar radiation for five models based on relative sunshine hours, air ambient temperature, latitude and precipitation have been studied for four different climatic conditions. The level of performance of the models has been analyzed by statistical indicators and the following can be concluded; 
1. The modified monthly daily mean global solar radiation prediction models for specific site show comparable results with measured global solar radiation.

2. Relative sunshine hours based models, are accurate in predicting global solar radiation in wet and cold, wet and warm climatic conditions.

3. Temperature and precipitation based model has been accurate in prediction of global solar radiation in hot dry and hot and humid climatic conditions.

4. Almorox and Rietveld modified models, based on relative sunshine hours are the most accurate models in prediction of global solar radiation in wet climatic conditions.

5. Gariepy modified model is the most accurate of the other model in prediction of global solar radiation in hot and dry, hot and humid climatic conditions.

6. The modified models can be used in prediction of global solar radiation in locations and sites that have similar climatic conditions, and in the design of solar applications for specific locations.

\section{References}

[1] C. Schileing,R. Meyer.F. Triels, High resolution for solar radiation assessment for Kenya, Final country report submitted to UNEP 2004.

[2] M. Bind, F. Miglietta, Estimating daily global radiation from air temperature and rainfall measurements, Climatic change.146 (1991) $117-124$.

[3] J.B. Almorox, Estimating global solar radiation from common meteorological data in Aranjuez Spain, Journal of Physics. 35 (2011) 53-64.

[4] Solar Radiation Estimation from the Measurement of Sunshine Hours over Southern Coastal region, Bangladesh. http://www.sciencepublishinggroup.com/j/ijsge2015(accessed on 06.01.17)

[5] E.A. Ahmad, .I Ulfat, Estimating global radiation in Turkey, Turkey journal of physics.29. (2005) 63-73.

[6] K. Bakirei, Correlation for estimating daily global solar radiation with hourly bright sunshine in Turkey,Energy journal of Turkey.4 (2009) 485-501.

[7] T. Muneer,S. Younes, S. Munawwar, Solar energy modeling, Renewable and Sustainable Energy.11(2007) 551-602.

[8] N. Kuman, S.P. Sharma, S.B. Saksena, Comparison of different models for estimating global solar radiation in Jharland (India).Smart grid and Renewable Energy.4(2013) 348-352.

[9] M.S. Gadiwala, A.Usman, K. Jamil, Empirical model for estimating of estimating of global solar radiation with sunshine hours on a horizontal surface in various cities of Pakistan, Pakistan Journal of meteorology.9 (2013) 18- 28.

[10] R. Mahamood, G. Hubbad, Effect of time and temperature observation in estimating of daily solar radiation for northern great plans USA, USA Agronomy Journal. 94 (2002) 723-733.

[11] S.A. Inmak, A.G. Inmak ,J.W. Jones, Solar and net radiation based on Equations for estimating Evapotranspiration in humid climates,Journal of irrigation and Drainage engineering. 129(2003) 336-347.

[12] M.R. Rietveld, A new method for estimating the regression coefficient for the formula relating solar radiation to sunshine,Agricultural meteorology.19 (1978) 234-252.

[13] M.J. Ahmed, G.N. Tiwari, Solar radiation model review, International journal of energy research. 35 (2010) $271-290$.

[14] M. Pauleseu, Z. Schulett, Performance assessment of global solar radiation model under Romanian climate, Renewable Energy. 29 (2004) 767-777.

[15] S.G. Jimmy, H.J. Math, Simulation of global solar radiation based on cloud observations, Solar Energy. 78 (2005) $157-162$.

[16] A. Angstrom, H. Prescott, Solar and terrestrial radiation, Quarterly Journal of Royal meteorological society.50 (1924) 121-125.

[17] J.A. Duffie, W.A. Beckman, John Willey and son, Solar engineering thermal processes, third ed., New York, 1991

[18] J. Glover, J.D.G. McGulloch, The empirical relationship between solar radiation hours and sunshine, Quarterly journal of the royal meteorological society. 84 (1958) 171-175.

[19] B.G. Akinoglu, A. Ecevit, Construction of quadratic model using modified Angstrom coefficient to estimate global solar radiation, Solar energy. 45 (1990) 85-92.

[20] J. Gariepy, Estimation of global solar radiation, International Report service of meteorology government of Quebec Canada. 25 (1980) 582601.

[21] C. Rensheng, K. Ersi,Y. Jianping, Validation of five global radiation models with measured daily data in China, Energy conversion and management.45 (2004) 1759-1769.

[22] A.A. Elagib, M.G. Mansell, New approach for estimating global solar radiation across Sudan, Energy conversion and management.41 (2000) 419-434,.

[23] R.J. Stone, Improved statistical procedure for the evaluation of solar radiation models. Solar Energy.51 (1993) $289-291$.

[24] C.P. Jacovide, Statistical procedures for evaluation of evapotranspiration computing models, Agriculture water management. 27 (1995) 365-371,

[25] J.I. De Sauze, R.M. Nicacio.R.M, M.N. Moura, Global solar radiation in Mexico, Renewable energy. 30(2005) $1203-1230$.

\section{AUTHOR PROFILES}

Patrick M.Wainaina has done his Masters degree in Engineering Systems and Management at Egerton University. I am currently taking my PhD in Renewable Energy at Egerton University in the Department of Industrial and Energy Engineering.

George. O. Owino has a PhD in Thermodynamics and is the current Chairman in the department of Industrial and Energy Engineering, Faculty of Engineering and Technology of Egerton University.

Musa .R. Njue, has A PhD. in Renewable Energy and is a senior Lectures and researcher in the Department of Agricultural Engineering, Faculty of Engineering and Technology of Egerton University. 